\title{
Impacts of Land Use Change on the Regional Climate: A Structural Equation Modeling Study in Southern China
}

\author{
Zhanqi Wang, Bingqing Li, and Jun Yang \\ School of Public Administration, China University of Geosciences, Wuhan 430074, China \\ Correspondence should be addressed to Zhanqi Wang; zhqwang@cug.edu.cn
}

Received 17 September 2014; Revised 17 February 2015; Accepted 23 February 2015

Academic Editor: Jinwei Dong

Copyright ( 2015 Zhanqi Wang et al. This is an open access article distributed under the Creative Commons Attribution License, which permits unrestricted use, distribution, and reproduction in any medium, provided the original work is properly cited.

\begin{abstract}
With the frequent human activities operating on the earth, the impacts of land use change on the regional climate are increasingly perceptible. Under the background of the rapid urbanization, understanding the impacts of land use change on the regional climate change is vital and significant. In this study, we investigated the relationships between land use change and regional climate change through a structural equation model. Southern China was selected as the study area for its rapid urbanization and different structure of land use among its counties. The results indicate that the path coefficients of "vegetation," "Urban and surrounding area," and "other" to "climate" are $-0.42,0.20$, and 0.46 , respectively. Adding vegetation area is the main method to mitigate regional climate change. Urban and surrounding area and other areas influence regional climate by increasing temperature and precipitation to a certain extent. Adding grassland and forestry, restraining sprawl of built-up area, and making the most use of unused land are efficient ways to mitigate the regional climate change in Southern China. The results can provide feasible recommendations to land use policy maker.
\end{abstract}

\section{Introduction}

Human activities have played a dominant role in land use change, especially in the recent decades [1]. With acceleration of urbanization and industrialization, the average income and living standard have been improved obviously. Hence, the increasing material demands have led to rapid buildup area expansion and resources development, all of which have largely influenced the land use structure [2]. Firstly, the phenomenon that a large number of rural population transfer to the city continuously adds the demand for living and production room, which has a lot of land surrounding cities replaced by asphalt, metal, buildings, vegetative cover, and other anthropogenic lands [2,3]. Secondly, in order to feed more people, forestry and grassland will be cultivated and nature land would be changed into cultivated and built-up land. Consequently, the land surface is changed significantly to provide more resources and room for human beings. The land use change, caused by human activities mentioned above, has generated a series of ecological and climatic problems and aroused widespread concern among scholars. So far, a great number of researches have documented the relationship of land use change and regional climate change. For example, Pielke Sr. pointed out that land use change played a first-order role in climate-forcing effect [1]. Cai and Kalnay put forward the view that two-thirds of warming over the past four decades was caused by land use change [4]. The Intergovernmental Panel on Climate Change reported that the addition of artificial land could raise the greenhouse gas in the air by fossil fuel burning, which contributed to the change of average temperature [5]. Deng et al. thought that land use and cover change could influence the ecosystems at local, regional, and global scales and affected climate change in the direct or indirect way [6]. Conversely, climate can influence the urban development, growth of vegetation, and production of cultivated land, among others. The climate change is one of the most important agents in the change of land use.

Now, it is widely accepted that the impacts of land use change on the regional climate change include two aspects which are biogeophysics and biogeochemistry [7]. The biogeophysical effects refer to the change of physical parameters such as surface roughness, albedo, reflective and surface hydrology and vegetation transpiration characteristics. These 
parameters are known for having close connection to the regional precipitation and temperature [8]. Meanwhile, the biogeochemical effects mainly refer to altering the chemical composition of atmosphere [9]. There are a lot of literatures which had contributed to the research of carbon and nitrogen storage during the process of land use change [10-13], which have significant impacts on the composition of atmosphere.

For those complicated relations between land surface's physical, chemical, and biological characteristics, the contributions of land use change to the regional climate system are different and some uncertainties are still existing in the current stage of investigation [14-16]. Massive methods are being applied to identify the impacts. For instance, the regional climate model which has high resolution can simulate the current climate and climate change by describing the change in boundary conditions of the land surface so as to analyze the effects of land use change on regional climate change $[15,17]$. Reliable land use information is necessary in the regional climate model. Keeping the capacity of analyzing the radiation, energy, water, and dynamics interaction between atmosphere and land surface, the land surface model is used to integrate with regional climate model [6]. Furthermore, land use change evaluation models such as econometric model, agent-based model, scenario development, and their integration are invited to assess and simulate the land use change and regional climate in the future [18-21]. Referring to previous researches, it is obvious that most of them study the impacts between land use change and regional climate through land surface parameters such as evapotranspiration, roughness, and leaf area index. However, the quantitative analysis by the data of land use and regional climate is insufficient. Hence, we think that the relationship between panel data of land use and regional climate can be revealed by empirical statistical method, which is helpful to recognize the impacts of land use change on regional climate.

Taking advantage of abundant forestry and water resources, Southern China is experiencing the fast growth of population and rapid development of economy. Since Southern China is facing the crucial period of accelerating industrialization and urbanization, the urban development and land use structure are quite different among the counties. It will vary the regional climate environment further. Considering its typical climatic condition, rapid urbanization, and significant differences of land use structure among counties, Southern China was selected as the case study area. Therefore, in this study, the impacts of land use change on the regional climate in Southern China were quantitatively analyzed from the county level. And based on a statistical model, the effect significance and direction of each land use classification are assessed. The results can be used to provide certain reference for the decisions making of land use planning and policy so as to mitigate the regional climate change by land use change in the area.

\section{Data and Methodology}

2.1. Study Area. Southern China (located between $18^{\circ} 10^{\prime} \mathrm{N} \sim$ $26^{\circ} 24^{\prime} \mathrm{N}$ and $104^{\circ} 26^{\prime} \mathrm{E} \sim 117^{\circ} 20^{\prime} \mathrm{E}$ ) is one of the seven geographic partitions in China. The study area has a total land area of $451900 \mathrm{~km}^{2}$ covering three provinces which are Guangdong Province, the Guangxi Zhuang Autonomous Region, and Hainan Province (Figure 1). It is not just an important grain production base but also an excellent base of tropical crops in China.

As a typical tropic and subtropics monsoon climate region, Southern China keeps the characteristics of rain, high temperature, and being evergreen. Its average temperature and precipitation are about $16.5^{\circ} \mathrm{C} \sim 25.9^{\circ} \mathrm{C}$ and $1000 \sim$ $2600 \mathrm{~mm}$, respectively. For the rich sunshine and water resources, its lush plants account for $63.71 \%$ of the total area in 2005 , most of which involve tropical rain forestry, monsoon forestry, and subtropical monsoon evergreen broad-leaved forestry. In recent years, the concerns of resources' rational use and protection have widely spread. Therefore, afforestation has been carried out frequently in Southern China.

With the rapid development of economy, the imbalanced development of agriculture, industry, and service industry results in the remarkable land use change in Southern China. Additionally, the imbalanced regional development causes the huge differences of regional land use. The irrational development and utilization of land resources have led to regional climate change to a certain extent. According to the temperature and precipitation data from meteorological observation station, it is clear that the temperature in Southern China coastal area is rising and the annual precipitation in southern China varies periodically. In order to optimize land use structure and mitigate the regional climate change, a series of plans were implemented, for example, ecological restoration projects [22]. Therefore, the exploration of land use change's impact mechanism on regional climate is significant and helpful to the policy making and sustainable development.

\subsection{SEM (Structural Equation Model Analyses Variables'} Relations by Covariance Matrix). Variables can be divided into four kinds: exogenous latent variables, endogenous latent variables, exogenous observed variables, and endogenous observed variables. Observed variables generally refer to objectives. By contrast, latent variables are difficult to be observed directly but can be indicated by several related observed variables. This new multivariate statistical analysis method integrated by traditional factor analysis and path analysis mainly describes two kinds of relationships: the relationships between latent and related observed variables and the relationships among latent variables [23,24]. To solve questions mentioned above, SEM is divided into measurement component and structural component. The measurement component deals with the measurement errors and relationships between latent and related observed variables [25]. It specifies latent variables as some linear functions of their observed variables. The structural component's function is to capture the impacts of exogenous latent variables on endogenous latent variables and the impacts of endogenous latent variables upon one another [26]. The based equations are as follows:

$$
\operatorname{SEM}\left[\begin{array}{ll}
\text { measurement component } & {\left[\begin{array}{c}
Y=\bigwedge_{Y} \eta+\varepsilon \\
X=\bigwedge_{X} \xi+\delta \\
\text { structural component }
\end{array}\right.} \\
\eta=B \eta+\Gamma \xi+\zeta,
\end{array}\right.
$$




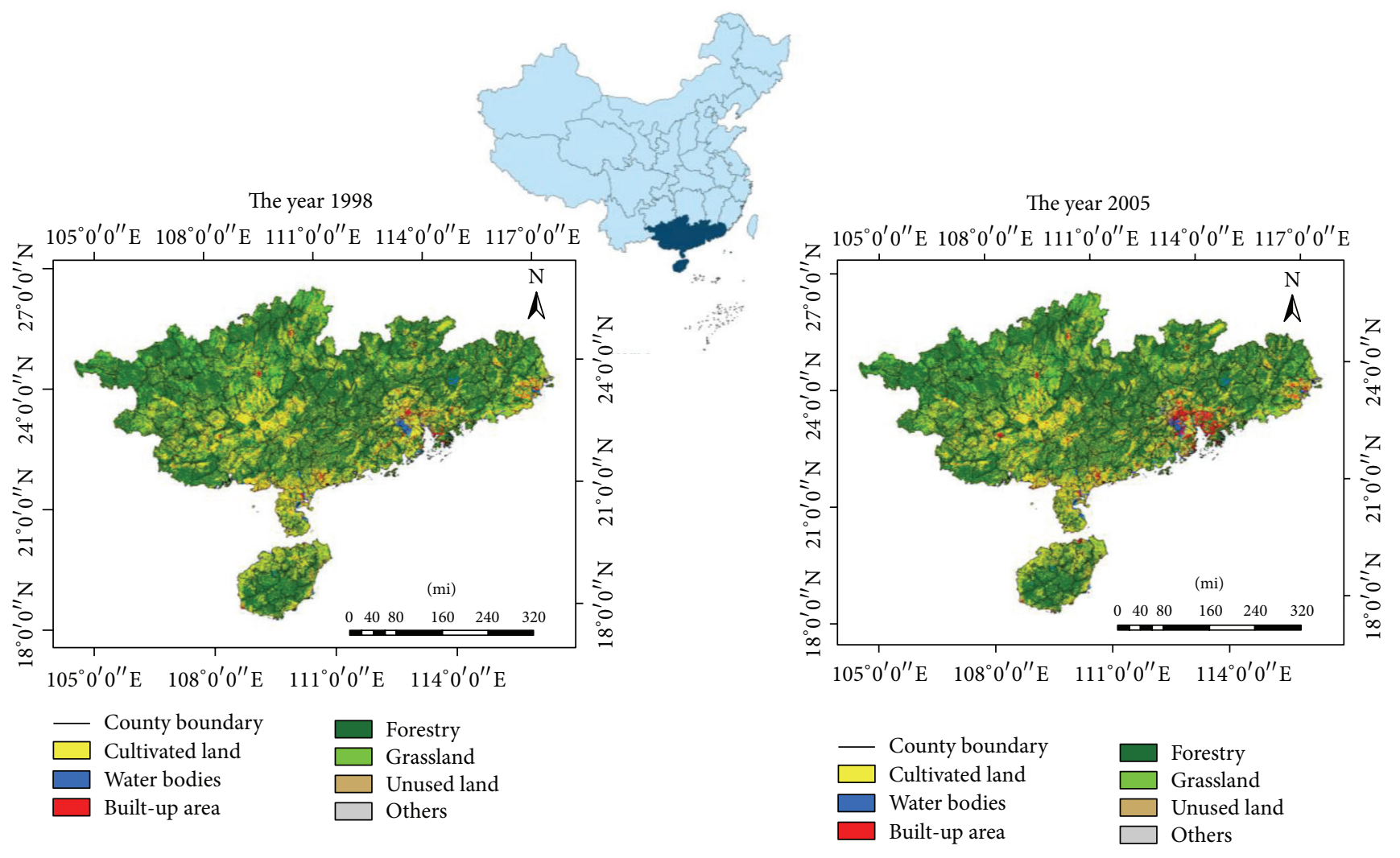

FIgURE 1: Location and the land use structure of Southern China.

where $Y$ is endogenous observed variable, $X$ is exogenous observed variable, $\eta$ are endogenous latent variables, $\xi$ are exogenous latent variables, and $\varepsilon, \delta$ are the measurement errors of $Y$ and $X$, respectively. $\wedge_{Y}, \wedge_{X}$ are the relationships between latent and corresponding observed variables; $B$ is the relationship among endogenous latent variables; $\Gamma$ is the impact of exogenous latent variable on endogenous latent variable; $\zeta$ is the residual of $\eta$, reflecting the irresoluble parts. Figure 2 is the sketch of SEM. These ellipses represent latent variables; the rectangles represent observed variables; the lines (called paths) indicate that there are relationships between variables; arrows show the effect direction; " $a-b$ " are path coefficients and " $c-h$ " are factor loadings. Path coefficients and factor loadings are main research objects used in measuring relationships. Generally, an SEM can have any number of latent and observed variables.

Compared with other traditional analysis methods, the SEM has the advantages of [26, 27]: (1) estimating multiple and interrelated dependence relationships at the same time; (2) allowing the measurement errors in the latent and observed variables; (3) the ability of dealing with unobserved variables making the model more flexible in application; (4) setting the entire relationship and goodness-offit; (5) handling nonnormal data; (6) accounting for missing data. Although SEM is mainly used in psychometrics and questionnaire analysis, it is worth noting that the model is being increasingly used in construction-related studies, where latent variables and measurement errors exist in

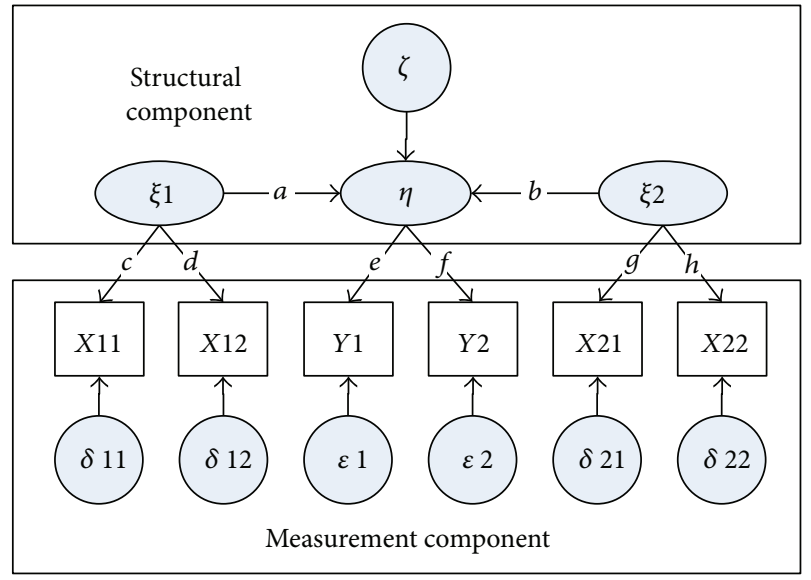

FIGURE 2: The sketch of SEM.

regression model [28]. Because there are measurement errors and a series of interrelated unobserved variables in the assumptions, the SEM is applied in this research.

The implementation of SEM includes three steps [29]. Due to the fact that SEM is obtained by the modification of existing hypothesis, the first step is to put forward a hypothesis SEM based on the advance verification of data structure. The verification estimates the relationships of observed variables and can be gotten by principal component 
analysis. Secondly, confirmatory factor analysis (CFA) is used to test the validity of hypothesis' measurement component. According to goodness-of-fit indices and theoretical meanings of variables, CFA will modify paths and fit model repeatedly until suitable corresponding relationships between latent and observed variables can be obtained. Finally, structural component is modified by the same method. Therefore, the factor loadings and path coefficients are explored. Most of the time, measurement and structural component are adjusting at the same time to get a more scientific model.

2.3. Data and Processing. The changes of land use and climate in Southern China were quantified by the differences between the years 1988 and 2005. The data used in the research mainly include (1) land use data of Southern China in the years 1988 and 2005 and (2) meteorological data in the years 1987 to 1989 and 2004 to 2006.

Firstly, the land use data (with a spatial resolution of $1 \mathrm{~km}$ $\times 1 \mathrm{~km}$ ) were extracted from remote sensing digital images of the US landsat TM/ETM satellite, which were obtained from the Resources and Environment Data Center of the Chinese Academy of Science. According to United States Geological Survey Classification, the land use was interpreted into seven parts of cultivated land, forestry, grassland, built-up area, water bodies, unused land, and others (most is the extension for coastline). The land use of each county was obtained by above data and administrative area boundary of the counties of Southern China.

Secondly, we used surface temperature and precipitation to reflect the regional meteorology. The original data were collected from meteorology stations. Kriging interpolation algorithm estimates unknown samples by original data and the distribution and spatial structure of samples. Compared with other methods, it reflects samples' spatial structure and takes the chance to work with extreme data. So it is good in regional estimation of temperature and precipitation. With about 60 meteorological stations in the study area and more than 30 around it (Figure 3), the original data were interpolated into $1 \mathrm{~km}$ resolution grid data by Kriging [30]. The climates of the years 1988 and 2005 were indicated by the average values of the years 1987 to 1989 and 2004 to 2006, respectively. Afterward, we counted the annual average temperature and precipitation of each county by arithmetic average method.

We can see from the above data that the land use of Southern China had changed greatly from 1988 to 2005. Cultivated land and built-up area had reduced $3859 \mathrm{~km}^{2}$ and increased $4369 \mathrm{~km}^{2}$, accounting for $3.57 \%$ and $36.88 \%$ of their total, respectively. Their changes were significant. Additionally, unused land, grassland, water bodies, and forestry had reduced $489 \mathrm{~km}^{2}, 1490 \mathrm{~km}^{2}, 35 \mathrm{~km}^{2}$, and $349 \mathrm{~km}^{2}$, accounting for $60.59 \%, 4.78 \%, 0.28 \%$, and $0.12 \%$, respectively. In addition to the built-up area, they were all reduced to a certain degree. The proportion of unused land was the most obvious. From 1988 to 2005, the annual average temperature and precipitation of Southern China had changed $0.67^{\circ} \mathrm{C}$ and

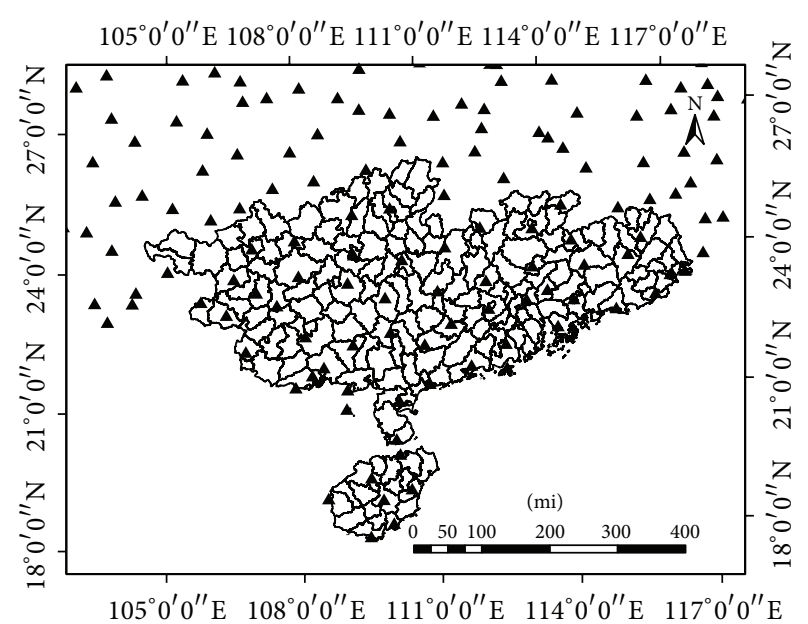

$\Delta$ Station
$\square$ County

FIGURE 3: The distribution of meteorological station.

$46.33 \mathrm{~mm}$. There was obviously upward trend in annual average temperature. However, the annual average precipitation fluctuated frequently and showed no obvious trend.

Principal component analysis is an important way to get the basic SEM hypothesis which is put forward based on the advance verification of data structure. Principal component analysis' dimensionality reduction function is to replace the original variables by fewer variables. The new variables contain most information of original variables. Comparing the different relationship coefficient between original and new variables, we can classify the original variables and conclude the new variables' meanings. Therefore, the data structure is clearly defined and SEM hypothesis can be constructed.

The strong correlation among variables is necessary for principal component analysis. Kaiser-Meyer-Olkin (KMO) determines the correlation through comparing the simple and partial correlation coefficient. The greater value indicates the stronger correlation. Bartlett test of sphericity is testing the independent character of variables by correlation coefficients matrix. The two tests are usually used to examine the appropriateness of data for principal component analysis performance. It is often suggested that $\mathrm{KMO}$ value should be of 0.5 as a minimal level and Bartlett test should be significant. For the land use data, the KMO valuing 0.594 and significant Bartlett test result were proving that the data were suitable for principal component analysis.

The principal component analysis of the land use data was carried out by statistics software SPSS, whose result was shown in Table 1. The "1," "2," and " 3 " represented the three principal components. The rotated component matrix which consisted of the numbers below the three principal components was presenting how close correlations between variables and principal components were. The number was called the factor loading of variable on principal component. Considering the closest correlation, each variable was classified to a principal component. Finally, 
TABLE 1: Rotated component matrix of principal component analysis.

\begin{tabular}{lccc}
\hline & \multicolumn{3}{c}{ Principal component } \\
& 1 & 2 & 3 \\
\hline Cultivated land & 0.746 & 0.025 & 0.422 \\
Forestry & -0.048 & -0.071 & 0.837 \\
Grassland & -0.065 & -0.026 & 0.817 \\
Water bodies & 0.788 & 0.265 & -0.132 \\
Built-up area & 0.823 & 0.015 & -0.257 \\
Unused land & 0.158 & 0.939 & -0.050 \\
Others & 0.065 & 0.953 & -0.046 \\
\hline
\end{tabular}

Notes: (1) principal component analysis was used; (2) orthogonal rotation method with Kaiser standardized was used and converged after four time iterations.

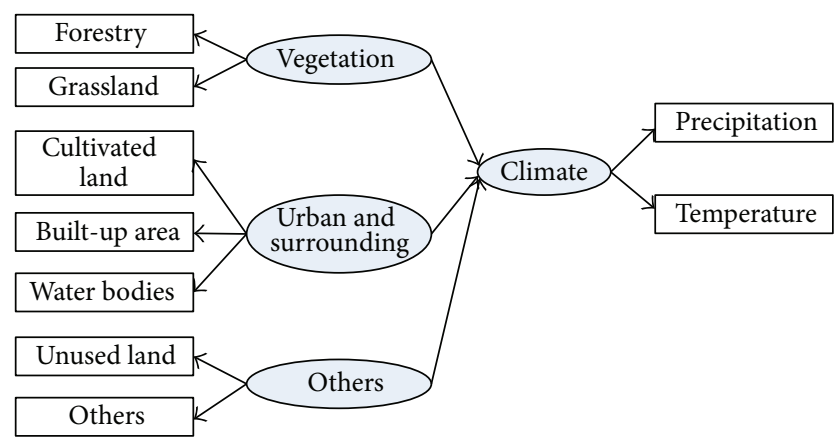

FIGURE 4: The basic hypothesis of structural equation model.

the land use classifications were divided into three parts: (1) vegetation area, including forestry and grassland; (2) urban and surrounding area, including cultivated land, built-up area, and water bodies; (3) other areas, including unused land and others. The cumulative contribution rate of the three principal components was $77.03 \%$, which judged the possession of original information. Generally, cultivated land is related to vegetation. However, from the perspective of change, the cultivated land has closer relationship to builtup area. This is because cultivated land keeps the capacity of feeding. For the convenience of travelling, built-up area is surrounded by cultivated land. The production of cultivated land also should satisfy the need of humanity. Consequently, cultivated land and built-up were classified into one principal component which was called the urban and surrounding area.

The basic SEM hypothesis of the research is shown in Figure 4 . The research took each county as a sample, so the sample size is 194. Based on above analysis, we regarded county's land use classifications as exogenous observed variables, regarded county's annual average temperature and precipitation as endogenous observed variables, regarded the three principal components as exogenous latent variables, and regarded climate as endogenous latent variable. The SEM reflected the relationships among above observed and latent variables.

2.4. Reliability Analysis. Reliability analysis is the foundation of this study's scientific benefit and properties. Reliability is used to test whether several variables can be used to explain the question together. So, it is also called the consistency of data. Before SEM analysis, the index of Cronbach's alpha is frequently used to investigate the consistency and reliability of measurements. When the Cronbach's alpha is greater than 0.7 , these data are suitable for SEM analysis [23, 29, 31]. Obtaining standard data by statistics software SPSS, the Cronbach's alpha value of above data was calculated. The value of 0.734 indicated that the data could be used for SEM analysis.

\section{Result and Discussion}

The software LISREL 8.80 was used to confirm and modify the basic hypothesis in our research. As an important statistical method, the maximum likelihood estimation method keeps the optimal characters of unbiasedness, consistency, and efficiency. The result will not be influenced by the unit of measurement [32]. Taking advantage of these characters, the maximum likelihood estimation method was selected as the fitting way. After fitting, model was estimated by goodnessof-fit indices. Some modifications which included adding and deleting paths took place based on the path coefficients, $T$-values, modification indices, and the meaning of each variable. Finally, we got the suitable structural equation model which revealed the impacts of land use change on the regional climate in Southern China.

3.1. Confirmatory Factor Analysis. By the confirmatory factor analysis, we got the path coefficients between observed variables and latent variables as well as the measurement errors of the observed variables. Considering that a large amount of literature had confirmed that precipitation and temperature were the key variables to reflect the area climate $[16,33]$, this confirmatory factor analysis was mainly attributed to the path between land use classifications and the three principal components. There were many indices involved in the assessment of overall goodness-of-fit of SEM, of which we selected the following important seven indices as evaluation criteria $[34,35]$. These indices measured the difference between the sample's covariance matrix and model-implied covariance matrix. Their meanings, equations, and criteria are shown in Table 2.

During the process of model modification, we deleted the path whose $T$-value was less than 1.96 and added the path by modification indices. Notably, all of the modifications were combined with proper theory analysis. As the result, the paths of "vegetation" $\rightarrow$ "cultivated land" and "vegetation" $\rightarrow$ "water bodies" were added to get a better fitting measurement model. The expansion of built-up area is based on the decrease of cultivated land due to the fact that the built-up area is surrounded by cultivated land. To satisfy the need of food, grassland, and forestry will be transformed to cultivated land. Therefore, the cultivated land has close relationship with "vegetation" and "urban and surrounding." Consequently, the path of "vegetation" $\rightarrow$ "cultivated land" was added. The land use maps (Figure 1) showed that the built-up area was always developed with water bodies, which kept the ability to reduce 
TABLE 2: The meanings and equations of indices of the goodness-of-fit.

\begin{tabular}{|c|c|c|c|c|}
\hline Index & Meaning & \multicolumn{2}{|r|}{ Equation } & Criterion \\
\hline$\chi^{2} / \mathrm{df}$ & $\begin{array}{l}\chi^{2} \text { is impacted by the difference between sample and } \\
\text { model-implied matrices. The small } \chi^{2} \text { represents the } \\
\text { good fitting of model and samples. Degree of freedom } \\
\text { (df) is the number of independent variables. } \\
\text { Considering that } \chi^{2} \text { is too sensitive to sample size, } \chi^{2} / \mathrm{df} \\
\text { is selected as a relative chi-square value }\end{array}$ & \multicolumn{2}{|r|}{-} & $<5$ \\
\hline$P$ & $\begin{array}{l}\text { The probability of error. } P \text { value and result's credibility } \\
\text { will change in the opposite direction. If } P<0.05 \text {, the } \\
\text { result is meaningful }\end{array}$ & \multicolumn{2}{|r|}{-} & $<0.005$ \\
\hline GFI & $\begin{array}{l}\text { Goodness-of-fit presents the proportion of covariance } \\
\text { in sample explained by implied model. Greater GFI } \\
\text { means the good explanation of dependent variables by } \\
\text { independent variables }\end{array}$ & \multicolumn{2}{|c|}{$1-\frac{\operatorname{tr}\left[\left(E^{-1} S-I\right)^{2}\right]}{\operatorname{tr}\left[\left(E^{-1} S\right)^{2}\right]}$} & $>0.9$ \\
\hline CFI & $\begin{array}{l}\text { Comparative fit index can avoid the underestimation of } \\
\text { fit in small samples. It also tests the difference between } \\
\text { the worst (independence) model and model of interest }\end{array}$ & \multicolumn{2}{|r|}{$\frac{\max \left(\chi_{T}^{2}-\mathrm{df}_{T}, 0\right)}{\mathrm{x}\left(\chi_{N}^{2}-\mathrm{df}_{N}, \chi_{T}^{2}-\mathrm{df}_{T}, 0\right)}$} & $>0.9$ \\
\hline RMSEA & $\begin{array}{l}\text { Root mean square error of approximation estimates the } \\
\text { discrepancy between model-implied and true } \\
\text { population covariance matrix per degree of freedom }\end{array}$ & \multicolumn{2}{|l|}{ Sqrt $\left\{\frac{\mathrm{m}}{-}\right.$} & $<0.08$ \\
\hline RMR & $\begin{array}{l}\text { Root mean square residual tests one kind of mean of } \\
\text { residual }\end{array}$ & Sqrt & $\frac{2 \Sigma \Sigma\left(s_{i j}-e_{i j}\right)^{2}}{p(p+1)}$ & $<0.05$ \\
\hline NFI & $\begin{array}{l}\text { Normed fit index reflects the proportion of worst } \\
\text { (independence) model } \chi^{2} \text { explained by model of } \\
\text { interest }\end{array}$ & & $\frac{\chi_{N}^{2}-\chi_{T}^{2}}{\chi_{N}^{2}}$ & $>0.9$ \\
\hline
\end{tabular}

Notes: $N$ is sample's size, $p$ is number of variables, $s_{i j}$ is sample's relation coefficient, $e_{i j}$ is model-implied relation coefficient, $S$ is sample's covariance matrix, $E$ is model-implied covariance matrix, $I$ is identity matrix, $\chi_{N}^{2}$ is chi-square of worst (independence) model, $\chi_{T}^{2}$ is chi-square of model of interest, $\mathrm{df}_{N}$ is worst (independence) model's degree of freedom, and $\mathrm{df}_{T}$ is model of interest's degree of freedom.

temperature and influence precipitation in Southern China. Hence, water bodies have close relationship with "vegetation" and "urban and surrounding." So the path of "vegetation" $\rightarrow$ "water bodies" was also added.

3.2. Structural Equation Modeling. As a good measurement model was obtained in the confirmatory factor analysis, the relationships among four latent variables in hypothesis were tested in structural model. There was no need for path modification. Therefore, we got the final structural equation model of the impacts of land use change on the regional climate (Figure 5). The numbers ranging from 0 to 1 on the lines of latent variables refer to observed variables presenting the standardized factor loading, which could reflect the related direction and significance. The numbers next to the arrows pointed to observed variables presenting the errors of observed variables. The numbers on the line between latent variables, which made up the main part of structural model, were called the standardized path coefficient.

Table 3 shows the measurement and structural component's estimate models, errors, $T$-values, and corresponding significance. Different from standardized factor loading and path coefficient in Figure 5, the coefficient of estimate models reflected the quantitative relationship between data. If $T$ value was larger than 1.96 and $P$ was below 0.001 , the path is significant. The SEM was composed of nine measurement equations and one structural equation. Accordingly, in addition to the path "Urban and surrounding" $\rightarrow$ "Climate," all the path coefficients had passed the significant test. It is widely known that the development of urban leads to climate change, so we did not delete this path. Therefore, we thought the SEM was valid. Table 3 is helpful to deepen the understanding of variables' relationships and test the significance of each path. However, because the standard coefficient is comparable, the analysis of the result is based on Figure 5.

Table 4 presents the results of goodness-of-fit of confirmatory factor analysis and structural equation modeling. All paths were based on theoretical analysis. For the confirmatory factor analysis and structural equation modeling, it showed that their $\chi^{2} / \mathrm{df}, P$ value, GFI CFI, RMR, and NFI fell well within their acceptable ranges but RMSEA was slightly out of its limit. This might be caused by weaker linkage between "urban and surrounding area" with "climate." On the one hand, the goodness-of-fit measure indices are sensitive to sample size and easy to be underestimated when sample size is relatively small [26]. On the other hand, like other statistical analyses, the statistical relationship or association cannot prove the must-be relationship but simply provides support to the logical and intuitive belief influence between the data [35]. So the best model should be established based on the proper theory and the result of goodness-of-fit. According to above analysis, we considered that this SEM whose indices were 


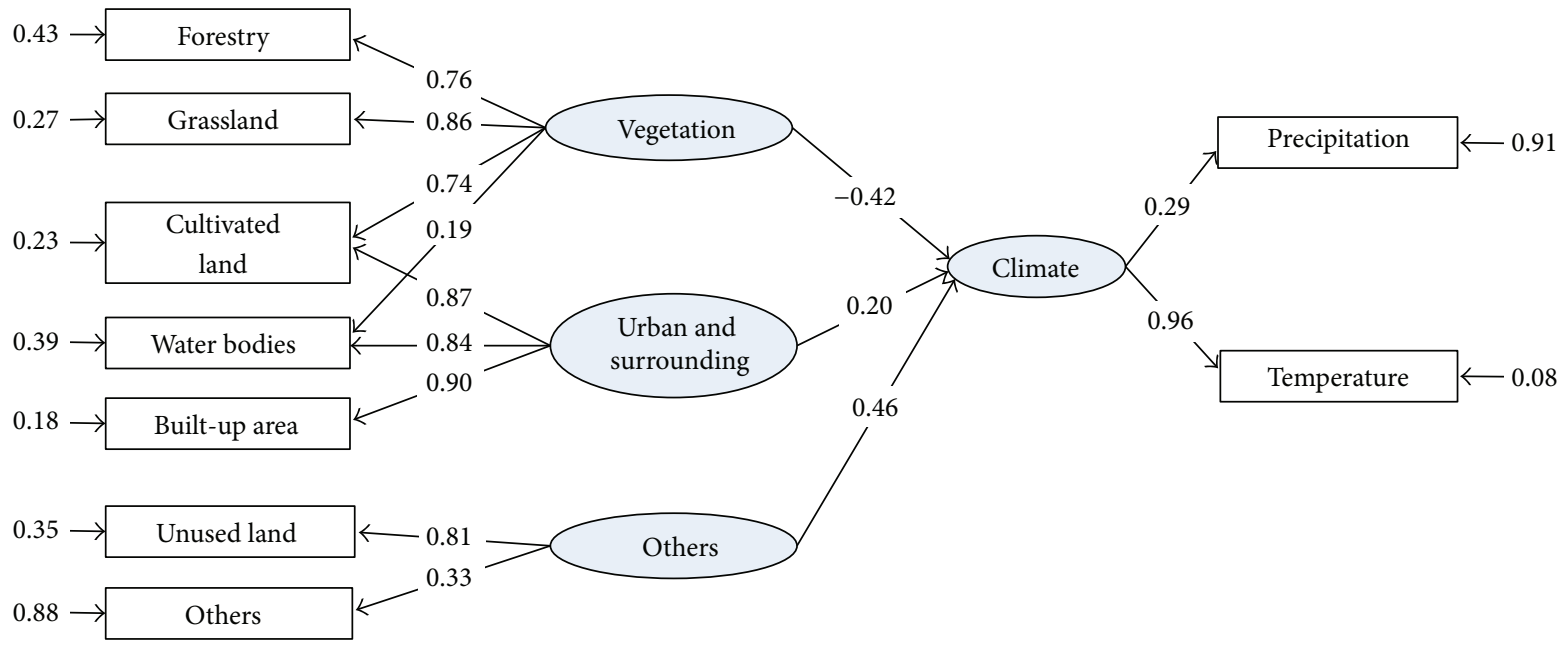

FIGURE 5: The structural equation model of the impacts of land use change on climate.

TABLE 3: The measurement and structural equations estimated by LISREL.

\begin{tabular}{|c|c|c|c|c|}
\hline Component & Estimate model & Error & $t$-value & Significance \\
\hline \multirow{9}{*}{ Measurement component } & Forestry $=0.76 \times$ vegetation & 0.43 & 11.52 & $P<0.001$ \\
\hline & Grassland $=0.86 \times$ vegetation & 0.27 & 13.49 & $P<0.001$ \\
\hline & $\begin{array}{l}\text { Cultivated land }=0.74 \times \text { vegetation }+0.87 \times \text { urban and } \\
\text { surrounding }\end{array}$ & 0.23 & $\begin{array}{l}10.26 \\
11.90\end{array}$ & $P<0.001$ \\
\hline & $\begin{array}{l}\text { Water bodies }=0.19 \times \text { vegetation }+0.84 \times \text { urban and } \\
\text { surrounding }\end{array}$ & 0.39 & $\begin{array}{l}2.97 \\
11.96\end{array}$ & $P<0.001$ \\
\hline & Built-up area $=0.91 \times$ urban and surrounding & 0.18 & 15.36 & $P<0.001$ \\
\hline & Unused land $=0.81 \times$ other & 0.35 & 6.24 & $P<0.001$ \\
\hline & Others $=0.33 \times$ other & 0.88 & 3.92 & $P<0.001$ \\
\hline & Precipitation $=0.29 \times$ climate & 0.91 & - & - \\
\hline & Temperature $=0.95 \times$ climate & 0.08 & 3.07 & $P<0.001$ \\
\hline \multirow{3}{*}{ Structural component } & \multirow{3}{*}{$\begin{array}{l}\text { Climate }=-0.42 \times \text { vegetation }+0.20 \times \text { urban and } \\
\text { surrounding }+0.46 \times \text { other }\end{array}$} & \multirow{3}{*}{0.38} & -2.74 & $P<0.001$ \\
\hline & & & 1.46 & $P<0.005$ \\
\hline & & & 2.34 & $P<0.001$ \\
\hline
\end{tabular}

TABLE 4: The result of goodness-of-fit.

\begin{tabular}{lccccccc}
\hline goodness-of-fit measure & $\chi^{2} / \mathrm{df}$ & $P$ & GFI & CFI & RMSEA & RMR & NFI \\
\hline Indices of confirmatory factor analysis & 2.43 & 0.0007 & 0.95 & 0.96 & 0.086 & 0.045 & 0.94 \\
Indices of structural equation modeling & 2.40 & 0.0006 & 0.95 & 0.96 & 0.085 & 0.044 & 0.93 \\
\hline
\end{tabular}

below but close to the criteria was acceptable. Consequently, the SEM was valid.

The standard factor loading and path coefficient revealed the significance and direction of relationships among the nine observed variables and four latent variables. The path coefficient of "vegetation" to "climate" $(-0.42)$ proved that vegetation area had dramatically negative impact on the regional climate change. That is to say, the addition of forestry, grassland, cultivated land, and water bodies could reduce the temperature and precipitation effectively. The path coefficient of "urban and surrounding" to "climate" (0.20) proved that the urban and surrounding area had positive impact on the climate change. Accordingly, the addition of cultivated land, water bodies, and built-up area could rise the temperature and precipitation to a certain extent. The path coefficient of "other" to "climate" (0.46) showed that other areas had positive impact on climate change, and the significance of effects was almost the same as "urban and surrounding." We thought this path coefficient was abnormal.

3.3. Analysis of SEM. The objective of this research is to carry out the quantitative impacts of land use change on 
the regional climate by a statistical model, so as to provide scientific understanding of the relationship between land use change and regional climate change to policy makers. According to the factor loadings, path coefficients of measurement, and structural models, we summed the opinions as follows.

(1) The structural model displays that all the three parts of vegetation area, urban and surrounding area, and other areas can impact regional climate to a certain extent. Compared with other two parts, vegetation area has negative relationship with regional climate change. First of all, adding vegetation area in low latitude area can mitigate temperature rise by affecting planetary energetic, atmospheric composition and hydrologic cycle [36]. Additionally, in coastal province, cities with high temperature increase their precipitation by evaporation and atmospheric circulation; thus the change of temperature and precipitation in Southern China has the same direction. Above analyses and the result of previous researches clearly indicate that decrease of vegetation resulting from deforestation and urbanization would make the temperature and precipitation increase in low latitude area $[37,38]$. Urban and surrounding area has positive relationship with climate change. Urban has a large number of heaters, motor vehicle, and other energy consuming devices, which transmit a lot of heat to air. Furthermore, a large number of buildings and roads increase heat capacity and conductivity of land. Therefore, adding urban and surrounding area leads to higher temperature. This result can be used to explain the urban heat island effect. The structural model shows that other areas which mainly include unused land and the extension for coastline have positive effects on regional climate change. Because the change of unused land was highly different among counties, the coefficient between "other" and "climate" calculated by SEM is relatively big. Referring to the land use change of Southern China in 1988 and 2005, unused land had reduced $489 \mathrm{~km}^{2}$, accounting for $60.59 \%$, which was the most significant change. A large proportion of unused land was changed to built-up area. Consequently, we think what this path indicates is that the rapid development of builtup area leads to the great climate change.

(2) The relationships between seven exogenous observed variables and three exogenous latent variables can be revealed in measurement model. Firstly, "forestry," "grassland," and "cultivated land" have strong and positive linkages with "vegetation," but the linkage between "water bodies" and "vegetation" is weaker relatively. Forestry, grassland, and cultivated land belong to vegetation area which keeps the characteristic of affecting a series of parameters of earth's surface. However, water bodies mitigate regional temperature and precipitation mainly by evaporation. Compared with the sea, the effect of evaporation of inland water bodies is less obvious, which results in the weaker link of water bodies in Southern China. Secondly, "built-up area," "cultivated land," and "water bodies" have strong and positive linkages with "urban and surrounding." Generally, the urban and surrounding area almost refers to the built-up area. In order to satisfy human's needs for food and water resources, the areas of cultivated land and water bodies have the trend to keep the same change direction with built-up area. This can be used to explain why the three variables are all related to "urban and surrounding," and "cultivated land" and "water bodies" have positive and slightly weaker relationships with "urban and surrounding" in SEM. Both unused land and others have positive linkages with other areas. Because unused land's distribution is much wider and larger than the extension of coastline, the SEM displays that "unused land" has closer linkage with "others."

(3) The urbanization of Southern China had changed the land use structure to a great extent, which had caused the obviously regional climate change. In the procession of slowing down the regional climate change, addition of vegetation is playing the most important role. For the majority of study area has been occupied by forestry which is much larger than grassland, the regional climate change is slightly less sensitive to deforestation than grassland development when they change the same area. The cultivated land and water bodies have the functions of mitigating regional climate change and feeding. Due to their weaker comprehensive impacts, the reclamation of grassland and forestry is against the mitigation of regional temperature and precipitation change. During the urbanization, the policy makers had put forward a series of efficient measures to protect the total amount of cultivated land such as land consolidation, land requisition-compensation balance, and land increase and decrease linked. We think the reasonable scales of cultivated land and water bodies should be judged by requirement. The change of unused land to vegetation can mitigate the regional climate change obviously. However, the change of unused land to built-up area can slightly mitigate the regional climate. This may be because the utilization of unused land can decrease the occupancy of vegetation. Hence, under the background of land intensive and sustainable use, taking full use of unused land plays an important role in mitigating the increasing temperature and precipitation.

\section{Conclusion}

In this paper, we applied SEM to analyze the impacts mechanism of land use change on the regional climate from the county level. Southern China was selected as case study area due to its typical climatic conditions, obvious land use conversion, and unbalanced regional development among counties. The contribution of this paper is to explore the potential relationship and effects between land use change and regional climate change by the application of SEM. This method is worth spreading. Besides, the identification of the relationship is helpful to generate land use policy options for authorities in Southern China. The conclusions of this research were summarized as follows.

Firstly, it is demonstrated that adding vegetation area is a significant effective way to mitigate regional climate change by reducing temperature and precipitation. Adding urban and surrounding area which enhances temperature and precipitation can affect regional climate to a certain extent. It seems that rapid urbanization contributes to the regional climate change of Southern China in recent decades. 
The influence of city expansion is relatively weaker. From the analysis of statistical data, other areas which mainly include unused land and extension of coastline show the significant and positive effect on the regional climate change. This path also reveals the positive relationship between city expansion and climate change.

Secondly, forestry and grassland both have strong linkages with vegetation area, which indicates the climate change can be mitigated by afforestation and adding grassland area. There is a significant and positive relationship between built-up area and urban and surrounding area. Accordingly, restraining sprawl of built-up area and adopting the strategy of sustainable development are important methods to mitigate regional climate change. Possessing the characteristics of mitigating regional climate change and feeding, cultivated land and water bodies both have relationships with vegetation area and urban and surrounding area. However, the suitable scales of them depend on the demand of humanity. Other lands mainly point to unused land in the study area, which can be used to ease the reduction of vegetation area caused by urbanization. This is a good way to solve the conflict between urban development and regional climate change.

It needs to be mentioned, however, that there are still some limitations in the research. For example, the result of good-of-fit is defective. In particular, it is because the relationship revealed by panel data is only a "probable and performance" relationship. That is to say, the structural equation model should be analyzed and applied based on theories and practices. To solve the problem, more data and variables are needed for the sample to improve model fit. Furthermore, the comparison among multitemporal data is helpful to get more credible results.

\section{Conflict of Interests}

The authors declare that there is no conflict of interests regarding the publication of this paper.

\section{Acknowledgments}

The research presented in this paper was supported by the National Basic Research Program of China (973 Program) (no. 2010CB950904). The data were collected by the Resources and Environment Data Center of the Chinese Academy of Science. The authors are grateful to Xiangzheng Deng for helpful comments on the early draft of the paper and to the editor and reviewers for their valuable comments and suggestions.

\section{References}

[1] R. A. Pielke Sr., "Land use and climate change," Science, vol. 310, no. 5754, pp. 1625-1626, 2005.

[2] J. Zhan, J. Huang, T. Zhao, X. Geng, and Y. Xiong, "Modeling the impacts of urbanization on regional climate change: a case study in the beijing-tianjin-tangshan metropolitan area," Advances in Meteorology, vol. 2013, Article ID 849479, 8 pages, 2013.
[3] Q. Weng, "Fractal analysis of satellite-detected urban heat island effect," Photogrammetric Engineering and Remote Sensing, vol. 69, no. 5, pp. 555-566, 2003.

[4] M. Cai and E. Kalnay, "Climate (communication arising) Impact of land-use change on climate," Nature, vol. 427, no. 6971, pp. 213-214, 2004.

[5] R. Pachauri and A. Reisinger, IPCC Fourth Assessment Report, Intergovernmental Panel on Climate Change(IPCC), Geneva, Switzerland, 2007

[6] X. Deng, C. Zhao, and H. Yan, "Systematic modeling of impacts of land use and land cover changes on regional climate: a review," Advances in Meteorology, vol. 2013, Article ID 317678, 11 pages, 2013.

[7] J. J. Feddema, K. W. Oleson, G. B. Bonan et al., "Atmospheric science: the importance of land-cover change in simulating future climates," Science, vol. 310, no. 5754, pp. 1674-1678, 2005.

[8] R. A. Betts, P. D. Falloon, K. K. Goldewijk, and N. Ramankutty, "Biogeophysical effects of land use on climate: model simulations of radiative forcing and large-scale temperature change," Agricultural and Forest Meteorology, vol. 142, no. 2-4, pp. 216233, 2007.

[9] J. Liu and X. Deng, "Impacts and mitigation of climate change on Chinese cities," Current Opinion in Environmental Sustainability, vol. 3, no. 3, pp. 188-192, 2011.

[10] J. D. Aber and C. T. Driscoll, "Effects of land use, climate variation, and $N$ deposition on $N$ cycling and C storage in northern hardwood forests," Global Biogeochemical Cycles, vol. 11, no. 4, pp. 639-648, 1997.

[11] L. P. Rosa, S. K. Ribeiro, M. S. Muylaert, and C. P. de Campos, "Comments on the Brazilian proposal and contributions to global temperature increase with different climate responses$\mathrm{CO}_{2}$ emissions due to fossil fuels, $\mathrm{CO}_{2}$ emissions due to land use change," Energy Policy, vol. 32, no. 13, pp. 1499-1510, 2004.

[12] S. Queguiner, E. Martin, S. Lafont, J.-C. Calvet, S. Faroux, and P. Quintana-Seguí, "Impact of the use of a $\mathrm{CO}_{2}$ responsive land surface model in simulating the effect of climate change on the hydrology of French Mediterranean basins," Natural Hazards and Earth System Science, vol. 11, no. 10, pp. 2803-2816, 2011.

[13] J. Dong, X. Xiao, S. Sheldon et al., "A 50-m forest cover map in Southeast Asia from ALOS/PALSAR and its application on forest fragmentation assessment," PLoS ONE, vol. 9, no. 1, Article ID e85801, 2014.

[14] V. K. Arora and A. Montenegro, "Small temperature benefits provided by realistic afforestation efforts," Nature Geoscience, vol. 4, no. 8, pp. 514-518, 2011.

[15] A. Kattenberg, F. Giorgi, H. Grassl et al., "Climate modelsprojections of future climate," in Climate Change 1995: The Science of Climate Change, Contribution of Working Group I to the Second Assessment Report of the Intergovernmental Panel on Climate Change, pp. 285-357, 1996.

[16] X. Gao, Y. Luo, W. Lin, Z. Zhao, and F. Giorgi, "Simulation of effects of land use change on climate in China by a regional climate model," Advances in Atmospheric Sciences, vol. 20, no. 4, pp. 583-592, 2003.

[17] H. Von Storch, E. Zorita, and U. Cubasch, "Downscaling of global climate change estimates to regional scales: an application to Iberian rainfall in wintertime," Journal of Climate, vol. 6, no. 6, pp. 1161-1171, 1993.

[18] R. B. Matthews, N. G. Gilbert, A. Roach, J. G. Polhill, and N. M. Gotts, "Agent-based land-use models: a review of applications," Landscape Ecology, vol. 22, no. 10, pp. 1447-1459, 2007. 
[19] W. D. Solecki and C. Oliveri, "Downscaling climate change scenarios in an urban land use change model," Journal of Environmental Management, vol. 72, no. 1-2, pp. 105-115, 2004.

[20] G. B. Bonan, "Effects of land use on the climate of the United States," Climatic Change, vol. 37, no. 3, pp. 449-486, 1997.

[21] R. N. Lubowskia, A. J. Plantingab, and R. N. Stavins, "Land-use change and carbon sinks: econometric estimation of the carbon sequestration supply function," Journal of Environmental Economics and Management, vol. 51, no. 2, pp. 135-152, 2006.

[22] Y. Qin, H. Yan, J. Liu, J. Dong, J. Chen, and X. Xiao, "Impacts of ecological restoration projects on agricultural productivity in China," Journal of Geographical Sciences, vol. 23, no. 3, pp. 404416, 2013.

[23] S.-C. Huang, S.-L. Lo, and Y.-C. Lin, "Application of a fuzzy cognitive map based on a structural equation model for the identification of limitations to the development of wind power," Energy Policy, vol. 63, pp. 851-861, 2013.

[24] X.-Y. Song, F. Chen, and Z.-H. Lu, "A Bayesian semiparametric dynamic two-level structural equation model for analyzing non-normal longitudinal data," Journal of Multivariate Analysis, vol. 121, pp. 87-108, 2013.

[25] S. P. Washington, M. G. Karlaftis, and F. L. Mannering, Statistical and econometric methods for transportation data analysis, Chapman and Hall, Boca Raton, Fla, USA, 2nd edition, 2011.

[26] T. F. Golob, "Structural equation modeling for travel behavior research," Transportation Research Part B: Methodological, vol. 37, no. 1, pp. 1-25, 2003.

[27] R. B. Keline, Principles and Practice of Structural Equation Modeling, The Guilford Press, New York, NY, USA, 2005.

[28] S. Rabe-Hesketh, A. Skrondal, and A. Pickles, "Generalized multilevel structural equation modeling," Psychometrika, vol. 69, no. 2, pp. 167-190, 2004.

[29] H. L. Dang, E. Li, I. Nuberg, and J. Bruwer, "Understanding farmers' adaptation intention to climate change: a structural equation modelling study in the Mekong Delta, Vietnam," Environmental Science \& Policy, vol. 41, pp. 11-22, 2014.

[30] M. R. Holdaway, "Spatial modeling and interpolation of monthly temperature using kriging," Climate Research, vol. 6, no. 3, pp. 215-225, 1996.

[31] J.-H. Wu, S.-C. Wang, and L.-M. Lin, "Mobile computing acceptance factors in the healthcare industry: a structural equation model," International Journal of Medical Informatics, vol. 76, no. 1, pp. 66-77, 2007.

[32] S.-Y. Lee and H.-T. Zhu, "Maximum likelihood estimation of nonlinear structural equation models," Psychometrika, vol. 67, no. 2, pp. 189-210, 2002.

[33] J. Al-Bakri, A. Suleiman, F. Abdulla, and J. Ayad, "Potential impact of climate change on rainfed agriculture of a semi-arid basin in Jordan," Physics and Chemistry of the Earth, vol. 36, no. 5-6, pp. 125-134, 2011.

[34] X. Cao, P. L. Mokhtarian, and S. L. Handy, "Do changes in neighborhood characteristics lead to changes in travel behavior? A structural equations modeling approach," Transportation, vol. 34, no. 5, pp. 535-556, 2007.

[35] B. Xiong, M. Skitmore, B. Xia, M. A. Masrom, K. Ye, and A. Bridge, "Examining the influence of participant performance factors on contractor satisfaction: a structural equation model," International Journal of Project Management, vol. 32, no. 3, pp. 482-491, 2014.

[36] G. B. Bonan, "Forests and climate change: forcings, feedbacks, and the climate benefits of forests," Science, vol. 320, no. 5882, pp. 1444-1449, 2008.
[37] S. A. Changnon Jr., "Rainfall changes in summer caused by St. Louis," Science, vol. 205, no. 4404, pp. 402-404, 1979.

[38] S. D. Chow and C. Chang, "Shanghai urban influences on humidity and precipitation distribution," GeoJournal, vol. 8, no. 3, pp. 201-204, 1997. 

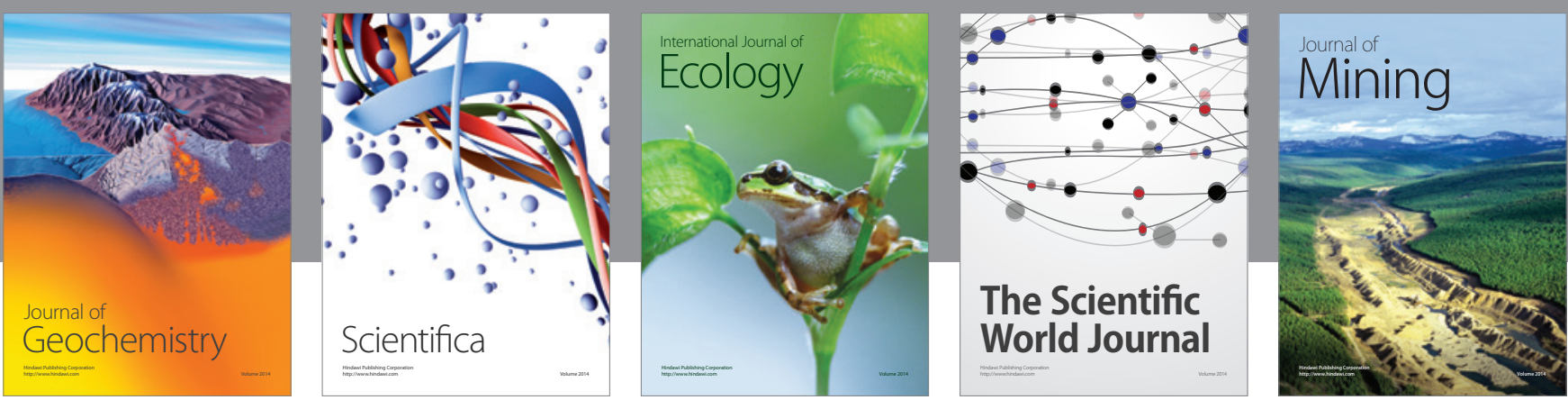

The Scientific World Journal
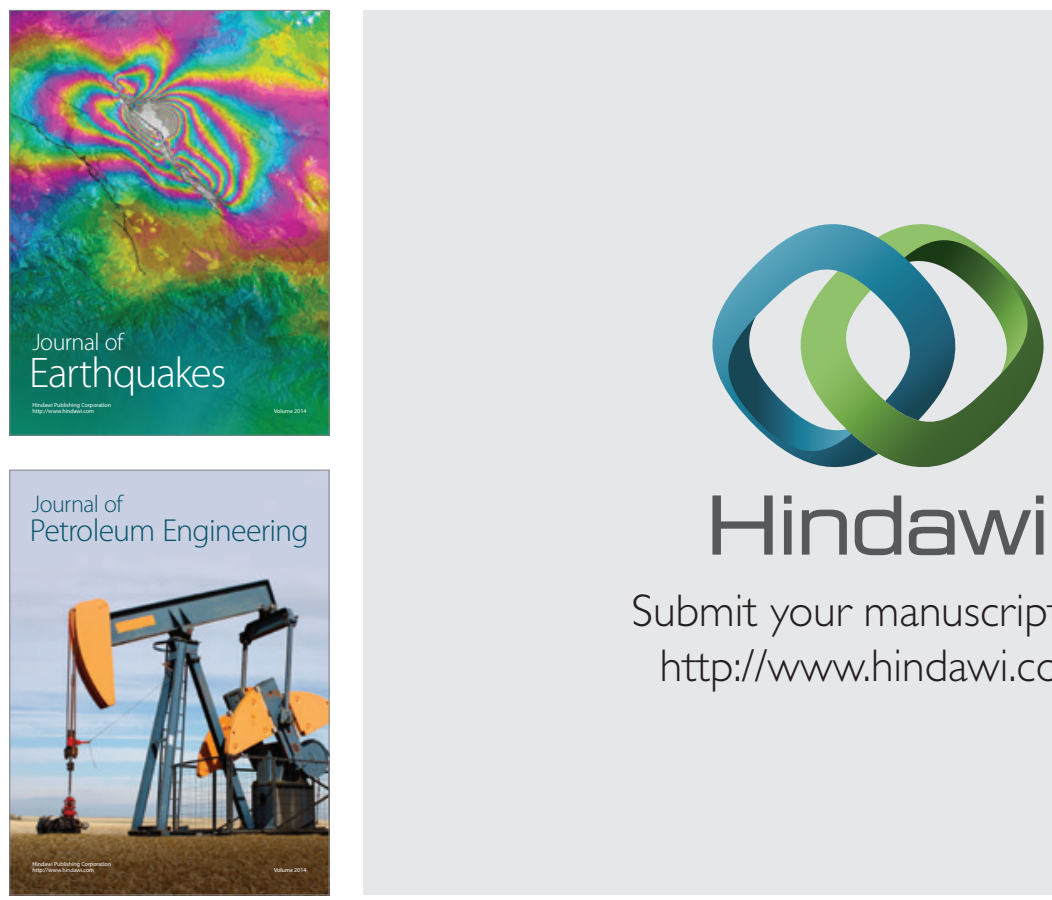

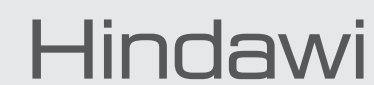

Submit your manuscripts at

http://www.hindawi.com
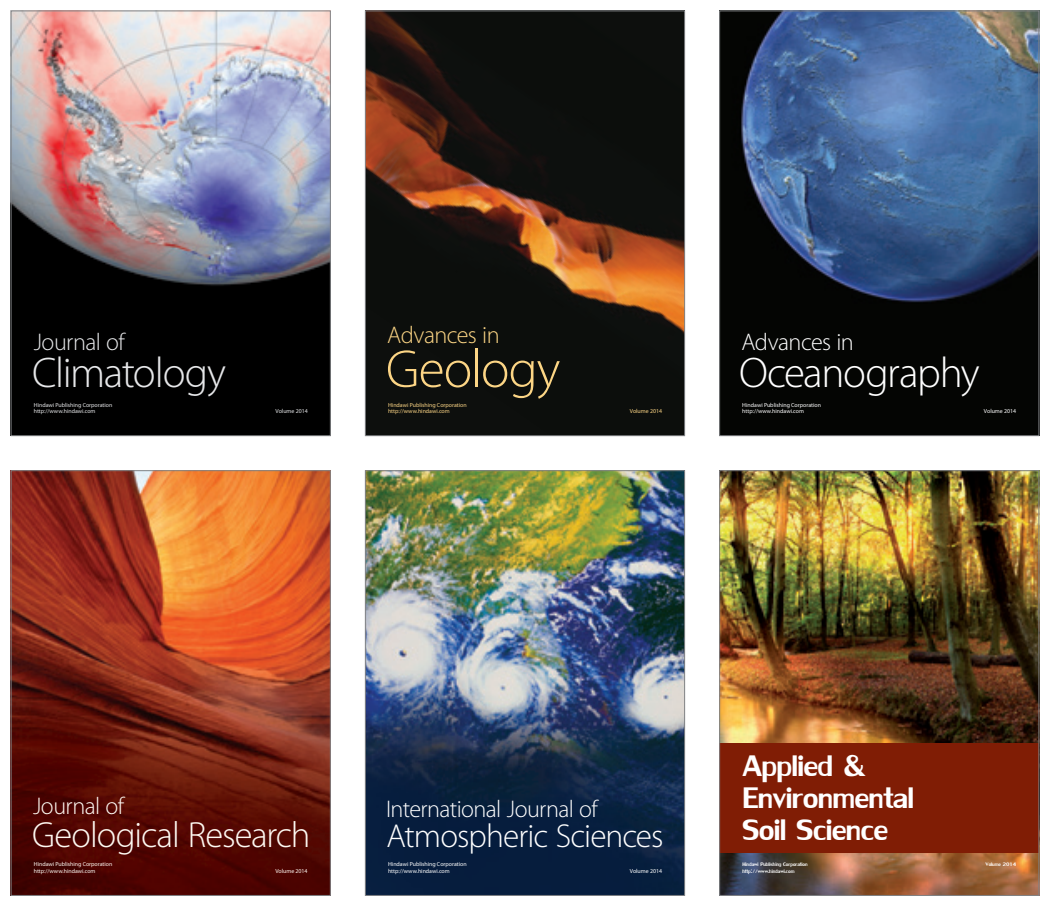
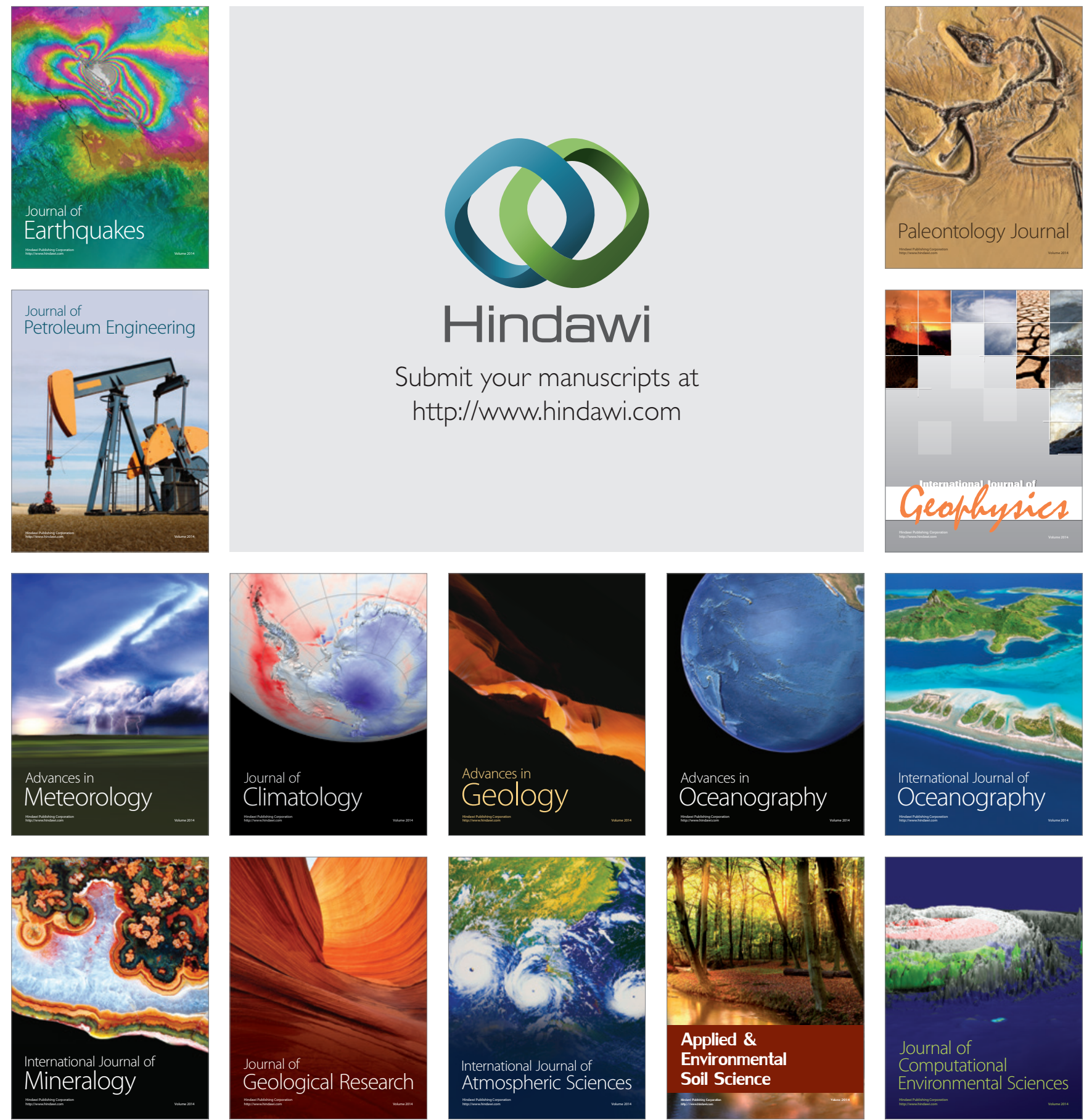